\title{
Short term and long term results after open vs. laparoscopic appendectomy in childhood and adolescence: a subgroup analysis
}

\author{
Matthias Kapischke ${ }^{1 *}$, Alexandra Pries ${ }^{2}$ and Amke Caliebe ${ }^{2}$
}

\begin{abstract}
Background: A comparative study was performed to compare quality of life after laparoscopic and open appendectomy in children and adolescents in a German General Hospital. The same study population was re-evaluated regarding their quality of life several years after operation.

Methods: Children and adolescents $(n=158)$ who underwent appendectomy for acute appendicitis between 1999 and 2001 were retrospectively analysed. Seven years after surgery those patients were interviewed applying a SF-36 questionnaire regarding their quality of life.

Results: For short term outcomes there was a trend towards reduced specific postoperative complications in the laparoscopically operated group (9.3 vs. 10.7\%). Significantly more patients in the laparoscopic group would recommend the operation procedure to family members or friends than in the open group. Among the evaluated patients there was a significantly higher satisfaction concerning size and appearance of their scars in the laparoscopic group. The results of the evaluation in the eight categories of the SF-36 showed similar results in both groups.

Conclusions: More patients with laparoscopic appendectomy appeared to be satisfied with their operation method as becomes evident by a higher recommendation rate and a higher satisfaction concerning their scars.
\end{abstract}

Keywords: Appendectomy, Paediatric surgery, Quality of life, SF-36

\section{Background}

Laparoscopic appendectomy (LA) has been established during recent years as an option to open appendectomy (OA) in the treatment of acute appendicitis in children and adolescents. The clinical benefit is seen controversial; minor reduction of post operative complications and pain $v s$. the cost of longer operative time as describe by some authors $[1,2]$. Results of randomised studies are conflicting [3,4]. Laparoscopic procedures in general promise to improve the health related outcome $[5,6]$. Whereas various laparoscopic approaches have shown their superiority regarding the classic factors (wound infection, postoperative pain, return to normal activity), randomized studies, focusing primarily on the patients

\footnotetext{
* Correspondence: mkapischke@web.de

'Department of Surgery, Klinik St. Georg, Lohmuehlenstrasse 05, D-20099

Hamburg, Germany

Full list of author information is available at the end of the article
}

perspective (such as quality of life) are less often conducted and the follow up time of most studies stops after half year. For appendectomy only a few studies focusing on quality of life in adults are available, providing a short follow up time of two weeks or six month $[7,8]$. There is no study comparing long term quality of life for children after OA and LA [9]. With these facts in mind a subgroup analysis for children was performed from already published data [10]. Target of this comparative study has been to clarify how younger patients who underwent appendectomy assess the long term course of events.

\section{Methods \\ Selection of patients \\ Between 1999 and 2001158 children (age 2 to16 years) underwent appendectomy (OA $\mathrm{n}=83$, LA $\mathrm{n}=75$ ) at the same hospital and were analysed retrospectively. Patients}

\section{Biomed Central}


with diagnostic laparoscopy followed by an incidental appendectomy were excluded. Only patients with the clinical diagnosis of acute appendicitis were selected for this study. Preoperative body mass index (BMI) of all patients was calculated.

\section{Surgical procedures}

Both modes of operations were performed by the same nine surgeons. Every surgeon performed more than 100 operations in every technique before he participated in our study. The mode of operation was chosen depending on the preferences of the operating surgeon. All surgeons performed both operations. OA was conducted under general anaesthesia applying a standard Mc Burney laparotomy at the right lower abdomen with buried stump.

LA with three port technique was carried out as described before [11]. The mesoappendix was divided by diathermy and the base of the appendix was resected with a laparoscopic stapler (Covidien or Ethicon, Germany). The appendix was extracted; in cases of a progressed inflammation an endobag was used. Finally the incisions were closed on the fascial level by an absorbable suture.

In all cases a single shot antibiotic prophylaxis with cefuroxime was administered preoperatively. Depending on the intraoperative findings a postoperative antibiotic therapy with cefuroxime (if considered necessary in combination with metronidazole) was commenced.

The intraoperative irrigation of the abdominal cavity with $0.9 \%$ sodium chloride solution depended on the stage of inflammation, as well as the utilization of a drain.

\section{Postoperative treatment and measurement}

The most frequently used postoperative analgesics were morphine and acetaminophen. Other morphine-derivative analgesics were usually not prescribed and if applied converted to morphine equivalent dose for analysis. Postoperative temperatures were routinely taken every morning orally. In case of repeated measurement the highest temperature during 24 hours was included for analysis. The white blood cell count (WBC) (physiological range from 4.5 to $10.5 / \mathrm{nl}$ ) were counted by SE 900 (Sysmex, Germany) and the C-reactive protein (physiological range $<0.5 \mathrm{mg} / \mathrm{dl}$ ) was measured by Analytic analyser 912 (Hitachi, Japan). These data were not measured for every patient every day. The frequency of these measurements depended on the clinical course.

Complications were divided into general complications that were not related to the surgical procedure and specific postoperative complications related to the operation procedure.

Wound infections were defined following the CDC (Centres of Disease Control and Prevention) definitions of surgical site infections (SSI) (modification 1992) [12].
Haematoma and seroma categorization followed the ultrasound criteria if there were no signs of infection to be detected in the patient. Patients returning to the hospital with complications following appendectomy during the first four weeks were included in the analysis.

\section{Short term outcomes of the study}

Investigated outcomes were operative time, required analgesics and postoperative complications within the first 30 days.

\section{Long term outcomes of the study}

In 2008 a quality of life questionnaire (Short-Form 36 Health Survey, SF 36) was distributed to all operated patients by mail. This questionnaire was supplemented by additional questions regarding the appendectomy such as satisfaction with the size and appearance of the scar (s), as well as the quality and intensity of pain. Additionally, patients were asked whether they would recommend the operation method to family members or friends. The original version of this questionnaire was published in [10]. Answers were evaluated using a point score: not at all $=1$, few $=2$, moderate $=3$ and very $=4$. A control question was asked twice in order to ensure the reliability of the answers. Additionally, body weight and height were monitored in order to evaluate the BMI at follow-up.

We analysed primarily the summarizing question regarding the recommendation of the experienced method. Moreover, the remaining questions of the self-developed supplement regarding the operation method and the eight scaled scores of SF-36 (physical functioning, physical role functioning, bodily pain, general health perceptions, vitality, social role functioning, emotional role functioning, mental health) were evaluated.

\section{Statistical analysis}

For short term outcomes the statistical analysis was performed using the Wilcoxon rank sum test, t-test (if normality could be assumed) and Pearson's $\chi^{2}$ test for categorical data.

A subgroup analysis was performed for children between 2 and 10 years and adolescents from 11 to 16 years. This discrimination addressed the question, whether any differences occurred depending on the patients' age. The evaluation was performed with Sigma Plot $^{\bullet}$ (Version 11, Systat Software Inc.).

For long term outcomes patients differing more than one point in their answer to the control question $(\mathrm{Q} 16$ and Q23) were excluded from further analyses (two patients). An additive unweighted score was used for the two questions concerning the appearance and the size of the scar (Q13 and Q14, minimum 2, maximum 8), and answers were categorized into two groups (2-5 and 6-8). 
The answers to the three questions concerning pain (Q20, Q21 and Q22) were summarized in an additive unweighted score (minimum 3, maximum 12), and answers were grouped into two categories (3-7 and 8-12).

Categorical outcomes were compared between laparoscopic and open appendectomy by Pearson's $x^{2}$ test. For the comparison of the BMI values, age and the scores of SF-36, a Wilcoxon rank sum test was applied. The statistical calculations were performed using the statistical program SPSS 15.0 for Windows ${ }^{\oplus}$ (Version 15.0.1).

All performed tests were two sided and a $p$-value smaller or equal to 0.05 is considered statistically significant.

This retrospective study is of exploratory nature and therefore no adjustment for multiple testing is applied. Results have to be verified in an additional prospective randomized double blinded study.

\section{Ethics}

This investigation was carried out in compliance with the Declaration of Helsinki. Laparoscopic and open appendectomies are part of standard surgical treatment without change in standard operating procedure and therefore did not require ethical approval. According to the Hamburg Hospital Law (Hamburgisches Krankenhausgesetz) the utilization of anonymized patient data for scientific research is part of the treatment agreement. This applies for a retrospective analysis of short term results as well. Written informed consent provided by the participants has been obtained prior re-evaluation. A counselling of the ethic committee (University of Kiel) was performed. For patients younger than 18 years the parents were consented as well and it was made clear for all participants that their participation is on voluntary basis.

\section{Results}

\section{Short term results}

Eighty-three children (34 female and 49 male), median age 11 years were treated by OA. Seventy-five patients (48 female and 27 male), median age of 12 years underwent LA. Both groups were not significantly different in sex-ratio and age (Table 1 ). Five patients (2 female and 3 male) in the laparoscopic group were converted to open appendectomy due to intraoperative findings (conversion rate $6.6 \%$ ). Conversions were necessary due to technical difficulties during the procedure. All cases of conversion were assigned to the laparoscopic group.

The degree of inflammation in both groups was equal in both groups without statistical significance (data not shown).

The median operative time (from skin incision to the end of closure) was significantly shorter for the laparoscopic (30 $\mathrm{min}$ ) versus open procedure with $38 \mathrm{~min}$ $(p=0.006$, Table 1$)$. A subgroup analysis for perforated appendicitis showed a comparable length of operation
Table 1 Demographic data open vs. laparoscopic appendectomy

\begin{tabular}{lccc}
\hline Parameter & $\begin{array}{c}\text { Open } \\
\text { appendectomy } \\
(\mathbf{n}=\mathbf{8 4})\end{array}$ & $\begin{array}{c}\text { Laparoscopic } \\
\text { appendectomy }(\mathbf{n}=\mathbf{7 5})\end{array}$ & $\begin{array}{c}\boldsymbol{p} \\
\text { Value }\end{array}$ \\
\hline $\begin{array}{l}\text { Female : male } \\
\text { Age [years] }\end{array}$ & $34: 49$ & $48: 27$ & 0.124 \\
$\begin{array}{l}\text { Median } \\
\text { (range) }\end{array}$ & $11(3-16)$ & $12(5-16)$ & 0.340 \\
$\begin{array}{l}\text { Operation time }[\mathrm{min}] \\
\begin{array}{l}\text { Median } \\
\text { (range) }\end{array} \\
\text { BMI }\left[\mathrm{kg} / \mathrm{m}^{2}\right]\end{array}$ & $38(14-92)$ & $30(11-90)$ & \\
Mean $\pm \mathrm{SD}$ & $17.4 \pm 3.2$ & & 0.006 \\
\hline
\end{tabular}

in both groups (49 min open vs. $48 \mathrm{~min}$ laparoscopic procedure; $p=0.792$ ).

Regarding required postoperative analgesics no differences for opiates and NSAID could be determined. The postoperative course of the available standard clinical inflammatory parameters (C-reactive protein, WBC and postoperative body temperature) was comparable for both procedures (data not shown). The rate of general postoperative complication was $2.4 \%$ in the open group (one urinary tract infection, one postoperative pancreatitis) and $2.6 \%$ in the laparoscopically operated group (one urinary tract infection and one thrombophlebitis of the arm). Both complications occurring in the laparoscopic group were conversions to OA. The rate of specific complications was $9.3 \%$ in the laparoscopic group and $10.7 \%$ in the open group ( $p=0.778$, Table 2$)$.

We also compared children ( $\leq 10$ years) and adolescents ( $>10$ years) concerning the benefit of either operative technique. In both groups we found a significant shorter operative time for the laparoscopic procedure without an increased complication rate. The other parameters did not show any significant differences (Table 3).

\section{Long term results}

Only fully completed and returned questionnaires were included in this evaluation. The re-evaluation rate after a median of seven years (range 5.5 - $8.2 \mathrm{yrs}$ ) in both groups was $59 \%$ (Table 4). Evaluation of the primary outcome showed that significantly more patients of the laparoscopic group would recommend this operative procedure to family members or friends than those of the open group (Figure 1A; $p<0.001$ ). For the secondary outcomes there was a significantly higher satisfaction of the patients of the laparoscopic group concerning size and appearance of scars ( $p=0.004$; Figure 1B).

Results of the evaluation of SF-36 in the eight categories are shown in Figure 2. The results are very similar 
Table 2 Specific minor and major postoperative complication (within the first $\mathbf{3 0}$ days)

\begin{tabular}{|c|c|c|c|c|}
\hline Minor complications & Open appendectomy $(n=84)$ & Laparoscopic appendectomy $(n=75)$ & $p$ Value & Thereof conversions \\
\hline Superficial Incisional SSI & $1(1.2 \%)$ & & & \\
\hline Deep Incisional SSI & $2(2.4 \%)$ & & & \\
\hline Haematoma & $1(1.2 \%)$ & $2(2.6 \%)$ & & 1 \\
\hline \multicolumn{5}{|l|}{ Port side hernia } \\
\hline $5 \mathrm{~mm}$ port & & $1(1.3 \%)$ & & \\
\hline $12 \mathrm{~mm}$ port & & $1(1.3 \%)$ & & \\
\hline$\Sigma$ & $4(4.8 \%)$ & $4(5.3 \%)$ & & 1 \\
\hline \multicolumn{5}{|l|}{ Major complications } \\
\hline Organ/Space SSI & $1(1.2 \%)$ & & & \\
\hline lleus & $2(2.4 \%)$ & $1(1.3 \%)$ & & 1 \\
\hline Relaparotomy & $2(2.4 \%)$ & $1(1.3 \%)$ & & 1 \\
\hline Bleeding & & $1(1.3 \%)$ & & \\
\hline$\Sigma$ & $5(6 \%)$ & $3(3.9 \%)$ & & 2 \\
\hline Total & $9(10.7 \%)$ & $7(9.3 \%)$ & 0.778 & 3 \\
\hline
\end{tabular}

for the two groups and no significant differences were found (physical functioning $\mathrm{p}=0.597$, physical role functioning $p=0.340$, bodily pain $p=0.899$, general health perceptions $p=0.734$, vitality $p=0.759$, social role functioning $p=0.877$, emotional role functioning $p=0.441$, mental health $p=0.552$ ).

Regarding the long term complications only one patient (OA) needed a reoperation due to a late intraabdominal abscess. A second OA patient suffered from an incisional hernia and required hernia repair (long term complication rate $5 \%$ ). In the laparoscopic group two patients needed a re-laparoscopy due to intraabdominal adhesions. Additionally, one patient who was converted from LA to OA

Table 3 Comparison of younger and older children

\begin{tabular}{|c|c|c|c|}
\hline & $\begin{array}{c}\text { Open } \\
\text { appendectomy }\end{array}$ & $\begin{array}{l}\text { Laparoscopic } \\
\text { appendectomy }\end{array}$ & $p$ Value \\
\hline \multicolumn{4}{|l|}{ Children 3-10 years } \\
\hline Number of patients & 59 & 29 & \\
\hline $\begin{array}{l}\text { Median operative } \\
\text { time [min] }\end{array}$ & 38 & 32 & 0.018 \\
\hline $\begin{array}{l}\text { Median morphine } \\
\text { dose [mg] }\end{array}$ & 0.5 & 0 & 0.0607 \\
\hline $\begin{array}{l}\text { Median acetaminophen } \\
\text { dose }[\mathrm{g}]\end{array}$ & 1 & 1 & 0.407 \\
\hline \multicolumn{4}{|l|}{ Children $11-16$ years } \\
\hline Number of patients & 24 & 41 & \\
\hline $\begin{array}{l}\text { Median operative } \\
\text { time [min] }\end{array}$ & 36 & 27 & 0.023 \\
\hline $\begin{array}{l}\text { Median morphine } \\
\text { dose [mg] }\end{array}$ & 0 & 0 & 0.962 \\
\hline $\begin{array}{l}\text { Median } \\
\text { acetaminophen } \\
\text { dose }[g]\end{array}$ & 1.125 & 2 & 0.480 \\
\hline
\end{tabular}

suffered from an incisional hernia and required a reoperation. Therefore a long term complication rate of $6 \%$ was calculated for the laparoscopic group.

\section{Discussion}

Discussion about the superiority of LA versus OA is as old as the laparoscopic procedure itself. In the meantime the advantages of the laparoscopic procedure in adults seem to be accepted [13]. In children the relevance of LA is still on debate [3]. Previous studies showed several disadvantages of LA in children: longer operative time, increased risk for intraabdominal abscess etc. $[1,14,15]$. However, meta-analysis and large database analyses were unable to confirm these findings [16]. Beside this, large cohort studies showed a rapid increase of the proportion of laparoscopically performed appendectomies in children over the last 10 years: the frequency of LA increased up to $50 \%[15,17]$. This correlates with the data presented here showing an increase of the laparoscopic proportion from $5 \%$ at the beginning of the evaluation to $75 \%$ at the end.

The proportion of perforated appendicitis in the study presented here is with 14 vs. $12 \%$ lower than in large cohort studies [15] but is comparable with other published studies [3]. Furthermore, the conversion rate of $6.6 \%$ in our study is similar to other retrospective and randomised studies in children [3]. The same holds true for early postoperative complications. Our rate of complications is being also comparable with large database analyses and multicentre analyses for children [15,18].

An often applied argument against LA is the longer operative time [19]. Compared to published studies focussing on children the operative time in our study has to be considered as quite short. The median operative time for LA is with 30 min significantly shorter than the 
Table 4 Results of the re-evaluation

\begin{tabular}{lccc}
\hline Parameter & $\begin{array}{c}\text { Open } \\
\text { appendectomy } \\
(\mathbf{n = 8 3 )}\end{array}$ & $\begin{array}{c}\text { Laparoscopic } \\
\text { appendectomy } \\
(\mathbf{n}=\mathbf{7 5})\end{array}$ & $\begin{array}{c}\boldsymbol{p} \\
\text { value }\end{array}$ \\
\hline $\begin{array}{l}\text { Answered questionnaires } \\
\text { [n] }\end{array}$ & 42 & 51 & \\
Female : Male [n] & $19: 23$ & $34: 17$ & 0.868 \\
Evaluation rate [\%] & 51 & 68 & 0.263 \\
$\begin{array}{l}\text { Age [years] at time of re- } \\
\text { evaluation median (range) }\end{array}$ & $19.1(13.8-23.2)$ & $18.5(12.6-22.8)$ & 0.195 \\
$\begin{array}{l}\text { BMl [kg/m²] median } \\
\text { (range) }\end{array}$ & $22.9(15.6-48.0)$ & $22.9(17.9-36.7)$ & 0.431 \\
$\begin{array}{l}\text { Postoperative interval } \\
\text { [years] median (range) }\end{array}$ & $7.2(5.7-8.2)$ & $6.5(5.5-7.2)$ & 0.094 \\
\hline
\end{tabular}

operative time for OA (38 min). The clinical relevance of this difference however, is only of minor importance [20].

The early postoperative results of this study are not the primary endpoint of this study and were only described to show that this is a representative study population which is comparable to published studies regarding the primary complication rate $[15,17]$.

Instead, our primary endpoint is the long term quality of life. The question investigated here is how operated children would apprehend possible constrictions following OA or LA and judge those in a different manner. It is interesting that, while for other laparoscopic procedures quality of life comparisons exist, for comparison of LA vs. OA in general only two studies could be retrieved evaluating this fact. Unfortunately, these studies included only patients older than 14 or 16 years $[7,8]$. Furthermore, these studies evaluated only the first half year after operation. This is a short period of time compared to our seven years re-evaluation period. We applied the SF-36 questionnaire an established tool for evaluation of quality of life $[9,21,22]$. This tool is applicable for children up to 14 years [23,24]. Even younger children are able to provide valid answers in such as questionnaires [25]. The differences between the laparoscopic and open operative procedure for appendectomy are not significant in this study as both operations are comparable with respect to all eight investigated scores of the SF-36 which is in accordance with other studies comparing laparoscopic and open procedure. In general measurable early postoperative advantages of the laparoscopic procedure appear to decrease over time [26,27].

Evaluation of questions concerning the operation directly shows a significantly higher satisfaction of the patients in the laparoscopic group concerning size and appearance of scars. The disposition to recommend the laparoscopic procedure to family members or friends may be based on this higher level of satisfaction with the scar.

The number of long term complications after seven years are equal in both operation groups since two patients in the open group and three patients in the laparoscopic group reported complications. Therefore, it may be considered interesting that intestinal adhesions were the main reason in the laparoscopic group. This matches with other findings which report that laparoscopic procedures do not reduce clinical relevant adhesions connected with pain or bowel obstruction [28].

Regarding the results of this study it should be taken into account that this is a retrospective study. No randomization was applied and the choice of operation method depended on the preferences of the surgeon. Nevertheless, randomized trials seldom report long term clinical outcomes such as quality of life. So, retrospective analyses can also give valuable information on postoperative quality of life [9]. In general retrospective analyses are
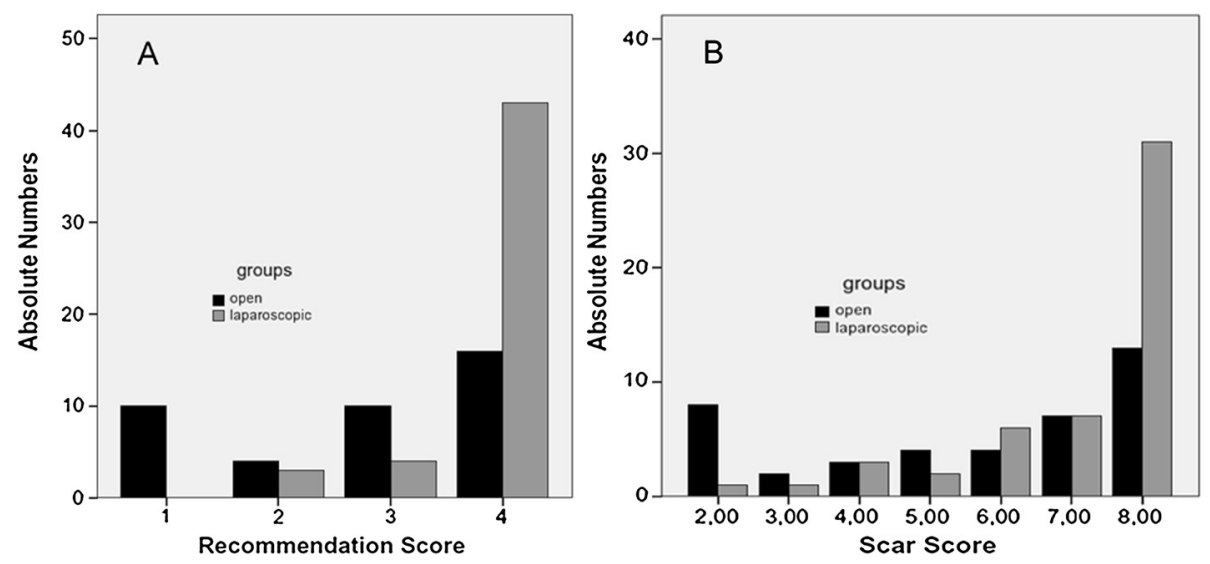

Figure 1 Readiness and satisfaction. A) Readiness to recommend the experienced operation procedure to relatives and friends; 1: not at all, 2: few, 3: moderate, 4: very. B) Postoperative satisfaction with appearance and size of the scar: 2: minimal satisfaction, 8: maximal satisfaction. 


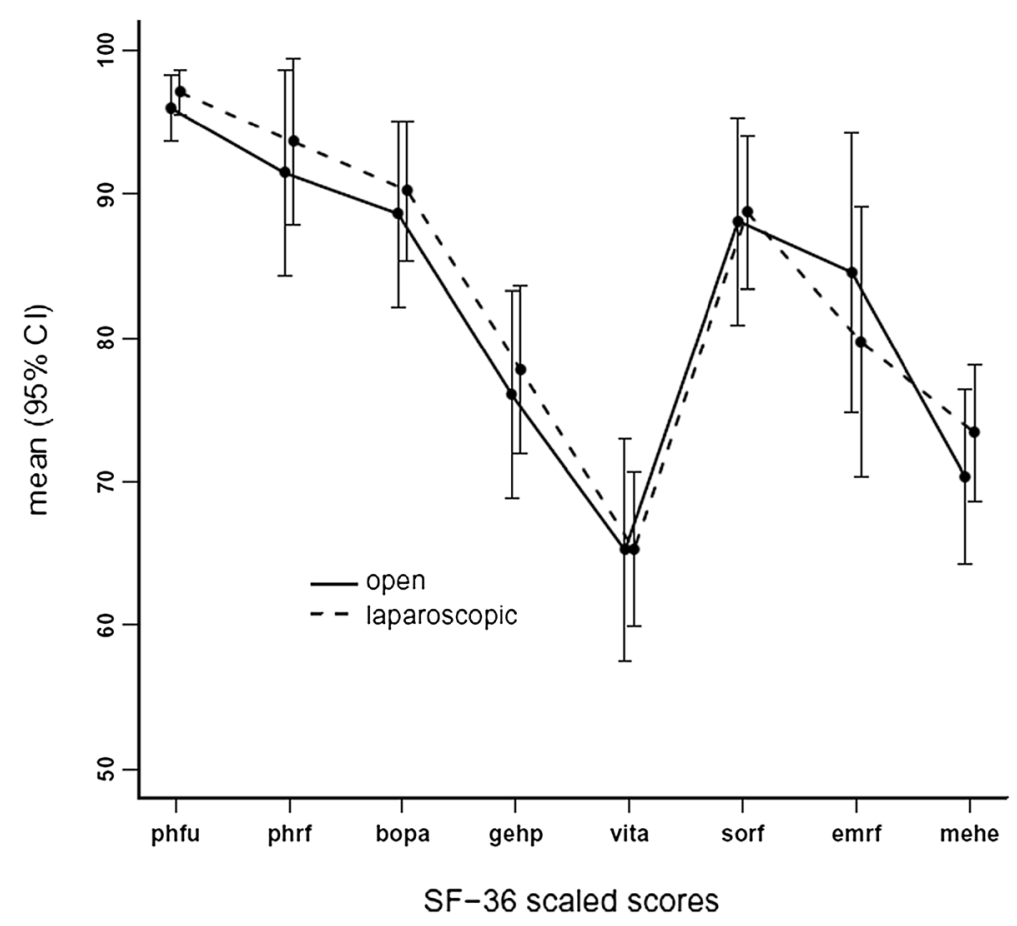

Figure 2 Results of the SF-36 questionnaire in the OA and LA groups. Phfu: physical functioning, phrf: physical role functioning, bopa: bodily pain, gehp: general health perceptions, vita: vitality, sorf: social role functioning, emrf: emotional role functioning, mehe: mental health, Cl: confidence interval.

included in meta-analyses in children given the limited availability of data [19].

The limited recovery rate of $59 \%$ may be seen as a further limitation of this study. Evaluating this recovery rate one has to keep in mind that even large data base analyses for appendectomy in children do not achieve higher follow-up rates $[15,17]$. Even though our sample size of approximately 80 patients per group may appear small it is still sufficient to show statistical significances for large to medium effect sizes. In this context it has to be pointed out that large sample size analyses have to be interpreted carefully since those are able to show statistical significances for small effect sizes with marginal differences which may be clinically unimportant $[20,29]$. Same holds true for the question if girls in the long term judge the cosmetic benefit higher than boys. Given the sample size a possible clinical significance should be seen with care. Unfortunately this holds true for the question if patients who were children or adolescents at the time of surgery would state their current quality of life differently as well. This is the reason for not showing a detail analysis regarding these two interesting facts as part of this manuscript.

It may be seen as a problem of the presented study that the patients are not blinded and a bias in the provided answers cannot be fully excluded. There is the possibility that the perception of LA as a more modern procedure may have influenced the patients' recommendation to family members and friends.

The long term results of this study correlate with other studies in adults regarding the quality of life for open $v s$. laparoscopic procedures. During the years after surgery the early postoperative advantages of the laparoscopic procedure minimize in comparison to the open procedure [26,27,30-32]. Only the cosmetic advantages experienced by the patient seem to remain, which would be an argument for the application of mini laparoscopic instruments ( $2.5 \mathrm{~mm}$ ports) or the use of single port techniques.

\section{Conclusions}

To our knowledge this is the first study which investigated quality of life in childhood more than seven years after operation. Neither OA nor LA seems to have relevant influence on the quality of life in younger patients in a long term evaluation. The postoperative results regarding cosmetic aspects appear to be an essential factor in rating an operative procedure in long term follow-up. Patients showed a higher satisfaction with their scars after laparoscopic surgery. The obtained data should be confirmed by a randomized blinded study. 


\section{Competing interests}

The authors declare that they have no competing interests.

\section{Authors' contributions}

MK: data evaluation, manuscript preparation. AP: Data interpretation and manuscript preparation. AC: Statistical analysis and manuscript draft. All authors read and approved the final manuscript.

\section{Author details}

'Department of Surgery, Klinik St. Georg, Lohmuehlenstrasse 05, D-20099 Hamburg, Germany. ${ }^{2}$ Institute for Medical Informatics and Statistics, Bldg 31 , University Hospital of Schleswig-Holstein, Campus Kiel, Arnold Heller Strasse 03, D-24105 Kiel, Germany.

Received: 23 February 2013 Accepted: 30 September 2013 Published: 1 October 2013

\section{References}

1. Horwitz JR, Custer MD, May BH, Mehall JR, Lally KP: Should laparoscopic appendectomy be avoided for complicated appendicitis in children? J Pediatr Surg 1997, 32(11):1601-1603.

2. Lejus C, Delile L, Plattner V, Baron M, Guillou S, Heloury Y, Souron R: Randomized, single-blinded trial of laparoscopic versus open appendectomy in children: effects on postoperative analgesia. Anesthesiology 1996, 84(4):801-806.

3. Little DC, Custer MD, May BH, Blalock SE, Cooney DR: Laparoscopic appendectomy: an unnecessary and expensive procedure in children? J Pediatr Surg 2002, 37(3):310-317.

4. Canty TG Sr, Collins D, Losasso B, Lynch F, Brown C: Laparoscopic appendectomy for simple and perforated appendicitis in children: the procedure of choice? J Pediatr Surg 2000, 35(11):1582-1585.

5. Sauerland S, Lefering R, Neugebauer EA: Laparoscopic versus open surgery for suspected appendicitis (Cochrane Review). Cochrane Database Syst Rev 2004, 18(4):25-30.

6. Neugebauer E, Troidl H, Kum CK, Eypasch E, Miserez M, Paul A, The Educational Committee of the European Association for Endoscopic Surgery: The E.A.E.S. Consensus Development Conferences on laparoscopic cholecystectomy, appendectomy, and hernia repair. Consensus statements-September,1994. Surg Endosc 1995, 9(5):550-563.

7. Katkhouda N, Mason RJ, Towfigh S, Gevorgyan A, Essani R: Laparoscopic versus open appendectomy: a prospective randomized double-blind study. Ann Surg 2005, 242(3):439-448. discussion 448-450.

8. Kaplan M, Salman B, Yilmaz TU, Oguz M: A quality of life comparison of laparoscopic and open approaches in acute appendicitis: a randomised prospective study. Acta Chir Belg 2009, 109(3):356-363.

9. Korolija D, Sauerland S, Wood-Dauphinee S, Abbou CC, Eypasch E, Caballero MG, Lumsden MA, Millat B, Monson JR, Nilsson G, et al: Evaluation of quality of life after laparoscopic surgery: evidence-based guidelines of the European Association for Endoscopic Surgery. Surg Endosc 2004, 18(6):879-897.

10. Kapischke M, Friedrich F, Hedderich J, Schulz T, Caliebe A: Laparoscopic versus open appendectomy-quality of life 7 years after surgery. Langenbecks Arch Surg 2011, 396(1):69-75.

11. Cox MR, McCall JL, Wilson TG, Padbury RT, Jeans PL, Toouli J: Laparoscopic appendicectomy: a prospective analysis. Aust N Z J Surg 1993, 63(11):840-847.

12. Horan TC, Gaynes RP, Martone WJ, Jarvis WR, Emori TG: CDC definitions of nosocomial surgical site infections, 1992: a modification of CDC definitions of surgical wound infections. Infect Control Hosp Epidemiol 1992, 13:606-608.

13. Li X, Zhang J, Sang L, Zhang W, Chu Z, Liu Y: Laparoscopic versus conventional appendectomy-a meta-analysis of randomized controlled trials. BMC Gastroenterol 2010, 10:129.

14. Thambidorai CR, Aman Fuad Y: Laparoscopic appendicectomy for complicated appendicitis in children. Singapore Med J 2008, 49(12):994-997.

15. Jen HC, Shew SB: Laparoscopic versus open appendectomy in children: outcomes comparison based on a statewide analysis. J Surg Res 2010, 161(1):13-17.

16. Nataraja RM, Teague WJ, Galea J, Moore L, Haddad MJ, Tsang T, Khurana S, Clarke SA: Comparison of intraabdominal abscess formation after laparoscopic and open appendicectomies in children. J Pediatr Surg 2012, 47(2):317-321.

17. Aarabi S, Sidhwa F, Riehle KJ, Chen Q, Mooney DP: Pediatric appendicitis in New England: epidemiology and outcomes. J Pediatr Surg 2011, 46(6):1106-1114.

18. Esposito C, Borzi P, Valla J, Mekki M, Nouri A, Becmeur F, Allal H, Settimi A, Shier F, Sabin M, et al: Laparoscopic versus open appendectomy in children: a retrospective comparative study of 2,332 cases. World J Surg 2007, 31(4):750-755.

19. Aziz O, Athanasiou T, Tekkis PP, Purkayastha S, Haddow J, Malinovski V, Paraskeva P, Darzi A: Laparoscopic versus open appendectomy in children: a meta-analysis. Ann Surg 2006, 243(1):17-27.

20. Grunkemeier $G L, W u$ Y, Furnary AP: What is the value of a $p$ value? Ann Thorac Surg 2009, 87(5):1337-1343.

21. Ware JE Jr, Gandek B, Kosinski M, Aaronson NK, Apolone G, Brazier J, Bullinger M, Kaasa S, Leplege A, Prieto L, et al: The equivalence of SF-36 summary health scores estimated using standard and country-specific algorithms in 10 countries: results from the IQOLA Project. International Quality of Life Assessment. J Clin Epidemiol 1998, 51(11):1167-1170.

22. Ware JE Jr, Kosinski M, Gandek B, Aaronson NK, Apolone G, Bech P, Brazier J, Bullinger M, Kaasa S, Leplege A, et al: The factor structure of the SF-36 Health Survey in 10 countries: results from the IQOLA Project. International Quality of Life Assessment. J Clin Epidemiol 1998, 51(11):1159-1165.

23. Bullinger M: [Assessment of health related quality of life with the SF-36 Health Survey]. Rehabilitation (Stuttg) 1996, 35(3):XVII-XXVII. quiz XXVII-XXIX.

24. Bullinger $M$, Alonso J, Apolone $G$, Leplege $A$, Sullivan M, Wood-Dauphinee S, Gandek B, Wagner A, Aaronson N, Bech P, et al: Translating health status questionnaires and evaluating their quality: the IQOLA Project approach. International Quality of Life Assessment. J Clin Epidemiol 1998, 51(11):913-923.

25. Varni JW, Limbers CA, Burwinkle TM: How young can children reliably and validly self-report their health-related quality of life?: an analysis of 8,591 children across age subgroups with the PedsQL 4.0 Generic Core Scales. Health Qual Life Outcomes 2007, 5:1

26. Violette A, Velanovich V: Quality of life convergence of laparoscopic and open anti-reflux surgery for gastroesophageal reflux disease. Dis Esophagus 2007, 20(5):416-419.

27. Thaler K, Dinnewitzer A, Mascha E, Arrigain S, Weiss EG, Nogueras JJ, Wexner SD: Long-term outcome and health-related quality of life after laparoscopic and open colectomy for benign disease. Surg Endosc 2003, 17(9):1404-1408

28. Scholin J, Buunen M, Hop W, Bonjer J, Anderberg B, Cuesta M, Delgado S, Ibarzabal A, Ivarsson ML, Janson M: Bowel obstruction after laparoscopic and open colon resection for cancer: Results of 5 years of follow-up in a randomized trial. Surg Endosc 2011, 25(12):3755-3760.

29. Abarbanell AM: Trends in pediatric appendectomy outcomes. J Surg Res 2010, 161(2):233-234.

30. Dowson H, Cowie A, Ballard K, Gage H, Rockall T: Systematic review of quality of life following laparoscopic and open colorectal surgery. Colorectal Dis 2008, 20:20

31. Bartels SAL, Vlug MS, Ubbink DT, Bemelman WA: Quality of lifer after laparoscopic and open colorectal surgery: a systematic review. World J Gastroenterol 2010, 16(40):5035-5041.

32. Gervaz P, Mugnier-Konrad B, Morel P, Huber O, Inan I: Laparoscopic versus open sigmoid resection for diverticulitis: long-term results of a prospective, randomized trial. Surg Endosc 2011, 25(10):3373-3378.

doi:10.1186/1471-2431-13-154

Cite this article as: Kapischke et al:: Short term and long term results after open vs. laparoscopic appendectomy in childhood and adolescence: a subgroup analysis. BMC Pediatrics 2013 13:154. 